Research Article

\title{
The Gap between Knowledge and Practice of Physical Activity in Medical Students of Delhi
}

\author{
Vandana Pandit', Jugal Kishore ${ }^{2}$ \\ ${ }^{1}$ MD Community Medicine, VMMC \& Safdarjung Hospital, New Delhi. \\ 2Director Professor \& Head of Department-Community Medicine, VMMC \& Safdarjung Hospital, New Delhi. \\ DOI: https://doi.org/10.24321/2455.9199.201905
}

I $\quad \mathbf{N} \quad \mathbf{F} \quad \mathbf{O}$

\section{Corresponding Author:}

Vandana Pandit, MD Community Medicine,

VMMC \& Safdarjung Hospital, New Delhi.

E-mail Id:

drvandanapandit@gmail.com

Orcid Id:

https://orcid.org/0000-0001-6025-9637

How to cite this article:

Pandit V, Kishore J. The Gap between Knowledge and Practice of Physical Activity in Medical Students of Delhi. Int J HealthCare Edu \& Med Inform 2019; 6(2): 1-6.

Date of Submission: 2019-08-17

Date of Acceptance: 2019-09-27
$\begin{array}{llllllll}\mathbf{A} & \mathbf{B} & \mathbf{S} & \mathbf{T} & \mathbf{R} & \mathbf{A} & \mathbf{C} & \mathbf{T}\end{array}$

Introduction: The lifestyle today has become more sedentary, and obesity and many non-communicable diseases are increasing among people. Medical students have a very demanding stressful life and have often been found to develop an unhealthy lifestyle.

Objectives: To find out the level of physical activity among the medical students, the gaps between their knowledge and practice and the prevalence of obesity among the students.

Methods: A cross-sectional study was done among 101 medical students of $3^{\text {rd }}$ year ( $35.6 \%$ were females and $64.4 \%$ were males) in a medical college in Delhi and assess their knowledge and practices of physical activities using a predesigned standard questionnaire (IPAQ). Data were analysed using Statistical Package for Social Sciences (SPSS) version 21 and descriptive statistics was presented.

Result: Thirty five (34.7\%) partcipants only had knowledge of recommended physical activities but only twenty nine (28.7\%) participants believed that the recommended physical activity is more than or equal to 150 minutes in a week. 41 (40.6\%) had Low activity, 45 (44.6\%) were sufficiently active or Moderately active, and 15 (14.8\%) had High activity. 20 (19.8\%) were overweight and 31 (30.7\%) were obese. Males [26(40\%)] were found to be significantly more obese than females [5(13.8\%)] $(P=0.001)$.

Conclusion: There is a high level of physical inactivity and obesity among medical students. Knowledge about physical activity has been increasing over the years among the medical students, but that knowledge is not converting into practice. There is a dire need for health promotional activity and behaviour change communication for increasing physical activity among medical students.

Keywords: Physical Inactivity, Life Style Disorder, Non-Communicable Diseases, Obesity 


\section{Introduction}

The global burden and threat of noncommunicable diseases constitute a major public health challenge in today's time. Non Communicable Diseases (NCDs), primarily cardiovascular diseases, cancers, chronic respiratory diseases and diabetes, are responsible for $63 \%$ of all deaths worldwide (36 million out of 57 million global deaths). ${ }^{1}$ Overall, about $13 \%$ of the world's adult population is obese, and $39 \%$ of adults are overweight. ${ }^{2}$ According to a study conducted by ICMR in four regions of India $54.4 \%$ were inactive, which is one of the risk factors of NCD. ${ }^{3}$ Physical inactivity levels are rising in many countries with major implications for the NCD and there is a need for promotion of a healthy lifestyle among people. A healthy lifestyle, proper nutrition and physical activity are protective factors against many diseases like hypertension, various cancers, obesity and related diseases.

Medical professionals play an important role in the management of obesity and related problems. However, being a part of the same society, these lifestyle diseases affect them too. The medical undergraduates lead a very demanding and stressful lifestyle and tend to develop an unhealthy lifestyle which predisposes them to become overweight and obese. ${ }^{4}$ It is often assumed that students in the health field have greater knowledge than other students, yet there is no evidence to indicate that this knowledge is translated into healthy dietary and lifestyle practices. ${ }^{5}$

Data reported by other studies have shown high prevalence of unhealthy dietary choices and lack of physical activity among medical students. ${ }^{6,7}$ However, there is a paucity of data in relationship of knowledge and practices of physical activities among medical students. presents the level of physical activity, the gaps between their knowledge and practice and the prevalence of obesity among the medical students.

\section{Methods}

A cross-sectional study was designed to collect the data from all students of $6^{\text {th }}$ semester of a Medical College in Delhi. Selection of students for participation in the study was non-probability purposive sampling. A semi-structured and self-administered questionnaire was converted into google form and pilot tested on a similar population, and necessary changes were made. The forms were administered as a link through WhatsApp. The final questionnaire had questions under the following headings: Socio-demographic, Physical Activity knowledge and the level of physical activity was assessed by International Physical Activity Questionnaire (IPAQ short form). IPAQ has questions regarding the activity done in the last seven days. The activities assessed were walking, moderate-intensity activities and vigorous-intensity activities. Frequency (measured in days per week) and duration (time per day) were collected separately for each specific type of activity.
Another measure of the volume of activity was computed by weighting each type of activity by its energy requirements defined in METs (Mets are multiples of the resting metabolic rate) to yield a score in MET-minutes. A MET-minute is computed by multiplying the MET score by the minutes performed. MET-minute scores are equivalent to kilocalories for a $60 \mathrm{~kg}$ person. MET scores used: Walking=3.3 METs, Moderate $\mathrm{PA}=4.0 \mathrm{MET}$ and Vigorous $\mathrm{PA}=8.0 \mathrm{METs}^{8}{ }^{8}$

Physical activity was classified into three categories:

- Low active (Category 1): This is the lowest level of physical activity. Those individuals who didn't meet criteria for Categories 2 or 3 are considered insufficiently active' [Category 1].

- Moderate active (Category 2): The minimum pattern of activity to be classified as sufficiently active. The minimum pattern of activity to be classified as sufficiently active is any one of the following 3 criteria: a) 3 or more days of vigorous activity of at least 20 minutes per day, or b) 5 or more days of moderate-intensity activity or walking of at least 30 minutes per day, or c) 5 or more days of any combination of walking, moderate-intensity or vigorous-intensity activities achieving a minimum of at least $600 \mathrm{MET}-\mathrm{min} /$ week.

Individuals meeting at least one of the above criteria would be defined as achieving the minimum recommended being considered moderate active [Category 2]. This category is more than the minimum level of activity recommended for adults in current public health recommendations but is not enough for total physical activity when all domains are considered. IPAQ measures total physical activity, whereas the recommendations are based on activity (usually leisuretime or recreational) over and above usual daily activities.

- High active (Category 3): A separate category labelled high level, which is a more active category [Category 3] computed for people who exceed the minimum public health physical activity recommendations.

Physical activity is to be categorized as High Active if any one of the following 2 criteria is met:

- Vigorous-intensity activity on at least 3 days and accumulating at least $1500 \mathrm{MET}-\mathrm{min} /$ week or,

- 7 or more days of any combination of walking, moderateintensity or vigorous intensity activities achieving a minimum of at least 3000 MET-min/week.

\section{Anthropometric Measurements}

Weight was measured using a bathroom electronic weighing scale with least count of $0.01 \mathrm{~kg}$. Students were allowed to stand on the machine without shoes to get the weight. Height was measured by stadiometer in the standing position without shoes.

Body Mass Index (BMI) was calculated using the formula: weight in $\mathrm{kg} /$ square of height in meters. 
Categories of BMI followed in this study was as per the ICMR guidelines: 18.5-22.9: normal BMI; 23-24.9: pre-obese and 25 and above: obese.

\section{Statistical Analysis}

The questionnaire was made in the google form. After data collection, the questionnaires were checked for completeness, and the data was cleaned for error and missing value. Variables were given suitable coding and entered in Microsoft Excel after preparing the master chart. Data analysis was done using Statistical Package for Social Sciences (SPSS) software licenced version 21.0. All the values were analysed using descriptive statistics to calculate for frequencies, mean, range. $P$ value of less than 0.05 was taken significant.

\section{Ethics}

Ethical permission was obtained from the Institutional ethical committee. Informed Consent was taken from all the participants before the study. Those had overweight, and obese were provided information to change their lifestyle.

\section{Results}

All the students of $3^{\text {rd }}$ year were invited to participate in the study. Out of a total of 140 students, 121 students showed interest in the study and gave consent for participation, but only 101 completed the questionnaire and got anthropometric measurements completed.

Table I.Distribution of the study participants according to sociodemographic details

\begin{tabular}{|c|c|}
\hline Sociodemographic Parameters & $\mathrm{N}=101(\%)$ \\
\hline \multicolumn{2}{|c|}{ Age in years } \\
\hline Mean age & 20.7 years \\
\hline \multicolumn{2}{|l|}{ Gender } \\
\hline Female & $36(35.6 \%)$ \\
\hline Male & $65(64.4 \%)$ \\
\hline \multicolumn{2}{|c|}{ Accommodation } \\
\hline Hosteler & $79(78.2 \%)$ \\
\hline Day scholar & $22(21.8 \%)$ \\
\hline \multicolumn{2}{|c|}{ Socioeconomic status (BG Prasad Scale)\# } \\
\hline Upper Class & $96(94.1 \%)$ \\
\hline Upper Middle Class & $6(5.9 \%)$ \\
\hline
\end{tabular}

\# None was classified under III-V Classes

The mean age of the study participants was 20.7 years. Out of the 101 participants, 36 (35.6\%) were female, and 65 (64.4\%) were male. 79 (78.2\%) students were hostelers, and $22(21.8 \%)$ were day-scholars. Most of the participants [96 (94.1\%)] had socioeconomic status of category 1 and a few [6 (5.9\%)] had category two according to B G Prasad scale (Table 1).
Table 2.Distribution of study participants according to knowledge about recommended physical activity for adults $(\mathbf{N}=35)$

\begin{tabular}{|c|c|}
\hline Recommended Minutes in a Week & $\mathbf{N}(\%)$ \\
\hline Below 150 minutes & $6(17.1)$ \\
\hline 150 minutes & $11(31.4)$ \\
\hline Above 150 minutes & $18(51.4)$ \\
\hline
\end{tabular}

Out of 101 participants, 35 (34.7\%) perceived that they knew what the recommendations about physical activity for adults are. However, only 29 (28.7\%) participants believed that the recommended physical activity is more than or equal to 150 minutes in a week (Table 2).

Table 3.Distribution of the participants according to their involvement in regular physical activity $(N=I 0 I)$

\begin{tabular}{|c|c|c|c|}
\hline $\begin{array}{c}\text { Involved in } \\
\text { Regular Physical } \\
\text { Activity }\end{array}$ & $\begin{array}{c}\text { Female } \mathbf{n} \\
\mathbf{( \% )}\end{array}$ & $\begin{array}{c}\text { Male } \mathbf{n} \\
\mathbf{( \% )}\end{array}$ & $\begin{array}{c}\text { Total N } \\
\mathbf{( \% )}\end{array}$ \\
\hline Yes & $22(61.1 \%)$ & $38(58.5 \%)$ & $60(59.4 \%)$ \\
\hline No & $14(38.9 \%)$ & $27(41.5 \%)$ & $41(40.6 \%)$ \\
\hline Total & 36 & 65 & 101 \\
\hline p-value=0.795
\end{tabular}

Students were asked if they are involved in regular physical activity or not and out the total 101, only 60 (59.4\%) students said that they are involved in regular physical activity. Among females 22 (61.1\%) and among males, $38(58.5 \%)$ of them reported being involved in regular PA (Table 3).

Table 4.Distribution of study participants according to self-reported minutes of physical activity in a usual week $(n=60)$

\begin{tabular}{|c|c|c|c|}
\hline $\begin{array}{c}\text { Self-reported } \\
\text { Minutes of physical } \\
\text { activity in a week }\end{array}$ & $\begin{array}{c}\text { Female } \mathbf{n} \\
\mathbf{( \% )}\end{array}$ & $\begin{array}{c}\text { Male } \mathbf{n} \\
\mathbf{( \% )}\end{array}$ & $\begin{array}{c}\text { Total } \mathbf{n} \\
\mathbf{( \% )}\end{array}$ \\
\hline Less than 150 mins & $16(72.7)$ & $11(28.9)$ & $27(45)$ \\
\hline $\begin{array}{c}\text { More than or equal } \\
\text { to } 150 \text { mins }\end{array}$ & $6(27.3)$ & $27(71.1)$ & $33(55)$ \\
\hline Total & $22(100)$ & $38(100)$ & $60(100)$ \\
\hline
\end{tabular}

p-value $=0.001$

However, among the 22 females who had reported to be involved in regular Physical Activity, a majority of them [16 (72.7\%)] did less than 150 minutes of Physical Activity in a week. Only $6(16.7 \%)$ of the females were doing 150 minutes or more Physical Activity in a week. Among males, 27 (36\%) of them were involved in 150 minutes or more physical activity in a week (Table 4). 
Table 5.Distribution of study participants according to the level of physical activity

\begin{tabular}{|c|c|c|c|}
\hline $\begin{array}{c}\text { Level of Physical } \\
\text { Activity }\end{array}$ & $\begin{array}{c}\text { Female } \mathbf{n} \\
\text { (\%) }\end{array}$ & $\begin{array}{c}\text { Male } \mathbf{n} \\
\text { (\%) }\end{array}$ & $\begin{array}{c}\text { Total } \mathbf{n} \\
\text { (\%) }\end{array}$ \\
\hline Inactive & $19(52.8)$ & $22(33.8)$ & $41(40.6)$ \\
\hline Sufficiently active & $15(41.7)$ & $30(46.2)$ & $45(44.6)$ \\
\hline High active & $2(5.5)$ & $13(20)$ & $15(14.8)$ \\
\hline
\end{tabular}

p-value $=0.06$

This difference came out to be significant $(P=0.001)$. The level of physical activity was also calculated using the IPAQ, and out the 101 participants 41 (40.6\%) had Low activity, $45(44.6 \%)$ were sufficiently active or Moderately active, and $15(14.8 \%)$ had High activity. Out of the 36 females, 19 (52.8\%) were inactive while 17 (47.2\%) of them were either moderate active or High active. Among the male participants $22(33.8 \%)$ had low activity, majority of them [43 (66.1\%)] were either sufficiently active or Moderately active but this difference between the male-female participants was not significant $(P=0.06)$ (Table 5).

Table 6.distribution of the study participants according to the type of physical activity they regularly involved in $(n=60)$

\begin{tabular}{|c|c|c|c|}
\hline Type of activity & Female & Male & Total $\mathbf{n}(\%)$ \\
\hline Running & $7(53.9)$ & $6(46.1)$ & $13(21.7)$ \\
\hline Gym & 0 & $9(100)$ & $9(15)$ \\
\hline brisk walking & $10(43.5)$ & $13(56.5)$ & $23(38.3)$ \\
\hline Dancing & $2(100)$ & 0 & $2(3.3)$ \\
\hline Yoga & $1(33.3)$ & $2(66.7)$ & $3(5)$ \\
\hline Sports & $2(20)$ & $8(80)$ & $10(16.7)$ \\
\hline Total & $22(36.7)$ & $38(63.3)$ & $60(100)$ \\
\hline
\end{tabular}

There was no significant difference in physical activity among hostellers and day-scholars $(\mathrm{P}=1.03)$. The participants who said were regularly involved in physical activity were found to have higher levels of physical activity when assessed through IPAQ ( $P=0.001)$

Most popular type of physical activity among the students who reported to be involved into regular physical activity was brisk walking [23 (38.3\%)], followed by running [ $13(21.7 \%)]$, sports [ $10(16.7 \%)]$, gym [9 (15\%)], yoga [3 (5\%)] and dancing [2 (3.3\%)]. However, gym and sports were found to be more popular among male participants (Table 6).

The most common reason for not doing regular PA was not having enough time due to the busy schedule [23 (57.5\%)], followed by laziness [9 (22.5\%)]. Three (7.5\%) of them stated that they never considered it (Table 7).
Table 7.Distribution of the participants according to reason for not involving in regular physical activity $(n=4 I)$

\begin{tabular}{|c|c|c|c|}
\hline Reasons & Female (\%) & Male (\%) & Total $\mathbf{n}(\%)$ \\
\hline no time & $8(34.8)$ & $14(65.2)$ & $23(57.5)$ \\
\hline not interested & $1(50)$ & $1(50)$ & $2(5)$ \\
\hline Laziness & $3(33.3)$ & $6(66.7)$ & $9(22.5)$ \\
\hline no motivation & 0 & $1(100)$ & $1(2.5)$ \\
\hline $\begin{array}{c}\text { never thought } \\
\text { about it }\end{array}$ & 0 & $3(100)$ & $3(7.5)$ \\
\hline $\begin{array}{c}\text { recovery from } \\
\text { injury }\end{array}$ & $1(50)$ & $1(50)$ & $2(5.0)$ \\
\hline & $12(29.3)$ & $26(70.7)$ & $41(100)$ \\
\hline
\end{tabular}

Table 8.Distribution of the study participants according to BMI categories $(\mathrm{N}=\mathrm{IOI})$

\begin{tabular}{|c|c|c|c|}
\hline BMI categories & $\begin{array}{c}\text { Females } \\
\mathbf{n}(\%)\end{array}$ & $\begin{array}{c}\text { Males } \mathbf{n} \\
(\%)\end{array}$ & $\begin{array}{c}\text { Total } \mathbf{n} \\
(\%)\end{array}$ \\
\hline Below18.5 & $1(2.8)$ & $1(1.5)$ & $2(2)$ \\
\hline $\begin{array}{c}\text { Between } 18.5 \text { to } \\
22.99\end{array}$ & $27(75)$ & $21(43.8)$ & $48(47.5)$ \\
\hline Between 24 to 24.99 & $3(8.3)$ & $17(26.2)$ & $20(19.8)$ \\
\hline Above 25 & $5(13.8)$ & $26(40)$ & $31(30.7)$ \\
\hline Total & $36(100)$ & $65(100)$ & $101(100)$ \\
\hline
\end{tabular}

$p$-value $=0.001$

\section{Obesity in Medical Students}

The mean weight of the participants was $67.47 \pm 1.3 \mathrm{~kg}$, and the mean BMI was 23.63. The mean BMI of females $(21.7 \pm 3)$ and males $(24.7 \pm 3.5)$. There were $2(2 \%)$ of the total participants were underweight, $20(19.8 \%)$ were overweight, and $31(30.7 \%)$ were obese. $27(75 \%)$ females had normal BMI and only 21(32.3\%) males had normal BMI. Males [26(40\%)] were found to be more obese than females [5(13.8\%)] ( $\mathrm{P}=0.001)$ (Table 8).

\section{Discussion}

In our study $28.7 \%$ of the participants had correct knowledge about the recommended physical activity which is much higher than the findings of a cross-sectional study done by Anand et al. in 2011 who found the knowledge of recommended physical activity was only $9.3 \%$ among the medical students of Delhi. ${ }^{9}$ We found through our study that $32.7 \%$ met the minimum recommended guidelines for physical activity. $27.3 \%$ of the girls and $69.2 \%$ of boys were involved in 150 minutes or more Physical Activity in a week. Anand et al. found a similar percentage (32.3\%) of the subjects adhered to then current recommended guidelines. Boys were found to be significantly more active than girls in both the studies when assessed for 
self-reported minutes of physical activity in a week. Looking at the IPAQ categories, in our study $40.6 \%$ had low activity, $44.6 \%$ were moderately active and $14.8 \%$ had high activity, but there was no significant difference in physical activity levels between boys and girls when assessed through IPAQ. In a study conducted among medical students of Bangalore by Padmapriya et al. in 2013, $15.4 \%$ and $43.2 \%$ of students showed low level and a moderate level of physical activity respectively, while $41.3 \%$ showed high levels of physical activity. ${ }^{10}$ However, Saranya et al. in the year 2016, found a higher level of physical activity among the medical students in south India. $10.5 \%$ were involved in light activity, $20.7 \%$ in moderate activity and $68.9 \%$ in vigorous activity. ${ }^{11}$ Despite of increasing levels of knowledge about physical activity among the medical students over the years, many studies have shown that the level of the physical activity has been decreasing among the future doctors.

In our study, the participants said that the most common reason was not having enough time due to busy schedule followed by laziness. In the study done by Rao et al. lack of time, laziness and exhaustion from academic activities were identified as important hindering factors among medical students who did not exercise. ${ }^{4}$ The reasons for not able to do regular exercise were very similar in both the studies.

In our study, $50.5 \%$ of participants were either overweight or obese, and the male participants were found to be more obese than female participants. In a study done by Gupta S et al. in 2009 , it was found that the $21.1 \%$ of medical students were obese. ${ }^{12}$ The study conducted by Anand et al. in 2011, showed that $34.8 \%$ were overweight or obese. ${ }^{9}$ We can see the prevalence of obesity, as well as the prevalence of inactivity, is also increasing among the medical students past few years. Even though we found that knowledge about physical activity is more, the level of physical activity is lower now.

\section{Strengths and limitations}

This study was designed to assess the knowledge and level of physical activity among the medical students, but one of the biggest limitations of our study was that the sampling method used was non-probability type. The participation was on a voluntary basis, so there is a possibility that only healthy students participated and those who were aware of their sedentary lifestyle or their obesity status did not participate in the study. However, a standard questionnaire IPAQ was used for assessing the physical activity levels, and the standard procedure was followed for taking the anthropometric measurements. The inadequacy of physical activity and BMI status was communicated back to the participants.

\section{Conclusion}

The knowledge about physical activity has been increasing over the years among the medical students, but that knowledge is not converting into practice. One of the most common reasons for not having an active life was found to be busy schedule due to academics. There is a dire need for health promotional activity and behaviour change communication for increasing physical activity as well as time management strategies. It is important that the future doctors have a healthy lifestyle for their own health so they become good role models for the people.

\section{Conflict of Interest: None}

\section{References}

1. World Health organization: Physical Activity and Adults [Internet]. Geneva: WHO;c 2010 [cited 18 July 2019]. Availablefrom: http://www.who.int/dietphy sicalactivity/factsheet_adults/en/.

2. Ntional Institute of Nutrition: Dietary Guidelines for Indians-A Manual [Internet]. Hyderabad: NIN; C2011 [cited 18 July 2019]. Available from: http://ninindia. org/dietaryguidelines forninwebsite.pdf.

3. Anjana R, Pradeepa R, Das AK, Deepa M, bhansali A, Joshi SR et al. Physical activity and inactivity patterns in India-results from the ICMR-INDIAB study (Phase-1) [ICMR-INDIAB-5]. Int J Behav Nutr Phys A 2014; 11(1): 26. Available from: https://ijbnpa.biomedcentral.com/ articles/10.1186/1479-5868-11-26 [PubMed/ Google Scholar].

4. Rao CR, Darshan BB, Das N, Ranjan V, Bhogun M, Gupta A. Practice of physical activity among future doctors: A cross sectional analysis. Int J of Prev Med 2012; 3(5): 365-369. [PubMed/ Google Scholar/ ResearchGate].

5. Sajwani RA, Shoukat A, Raza R, Shiekh MM, Rashid Q, Siddique MS et al. Knowledge and practice of healthy lifestyle and dietary habits in medical and non-medical students of Karachi, Pakistan. J Pak Med Assoc 2009; 59(9): 6505. Available from: https://scialert.net/ abstract/?doi=pjn.2015.892.897 [PubMed/ Google Scholar].

6. Sakamaki R, Toyama T, Amamoto R, Liu CJ, Shinfuku N. Nutritional knowledge, food habits and health attitude of Chinese university students-a cross sectional study. Nut J 2005; 4: 4. Available from: https://nutritionj. biomedcentral.com/articles/10.1186/1475-2891-4-4 [PubMed/ Google Scholar].

7. Musaiger AO, Awadhalla MS, Al-Mannai M, AlSawad M, Asokan GV. Dietary habits and sedentary behaviors among health science university students in Bahrain. Int J Adoles Med Health 2015; 29: 2. Available from: https:// www.degruyter.com/view/j/ijamh.2017.29.issue-2/ ijamh-2015-0038/ijamh-2015-0038.xml?lang=en [PubMed/ Google Scholar/ ResearchGate].

8. IPAQ: IPAQ scoring protocol 2004 - International Physical Activity Questionnaire [Internet]. 2018 [cited 18 July 
2019]. Available from: https://sites.google.com/site/ theipaq/scoring-protocol.

9. Anand T, Tanwar S, Kumar R, Meena GS, Ingle GK. Knowledge, attitude and level of physical activity among medical undergraduate students in Delhi. Indian J Med Sci 2011; 65(4): 133-142. [PubMed/ Google Scholar]

10. Padmapriya K, Krishna P, Rasu T. Prevalence and patterns of physical activity among medical students in Bangalore, India. Electronic physician 2013; 5(1): 606-610. Available from: http://www.ephysician.ir/ index.php/browse-issues/year-2013-volume-5/year2013-volume-5-issue-1/77-prevalence-and-patternsof-physical-activity-among-medical-students-inbangalore-india [PubMed/ Google Scholar].

11. Rao C, Saranya S, Kumar SC, Kamath V, Kamath A. Dietary habits and physical activity among medical students of a teaching hospital in South India: A descriptiveanalysis. Trop J Med Res 2016; 19(2): 172177. Available from: http://www.tjmrjournal.org/ article.asp?issn $=1119-0388$; year $=2016$; volume $=19$;iss ue=2; spage=172; epage=177; aulast=Saranya [PubMed/ Google Scholar [Google Scholar].

12. Gupta S, Ray T, Saha I. Overweight, obesity and influence of stress on body weight among undergraduate medical students. Indian J Community Medicine 2009; 34(3): 255-257. Available from: http://www.ijcm.org.in/ article. asp? issn $=0970-0218$; year $=2009$; volume $=34$;is sue $=3$; spage $=255$; epage $=257$; aulast $=$ Gupta [PubMed/ Google Scholar]. 